\title{
El significado de la frontera en la historia americana*
}

\author{
Frederick Jackson Turner
}

In boletín reciente del superintendente del censo de 1890 aparecen estas significativas palabras: "Hasta 1880 incluido, el pais tenía una frontera de colonización provisional, pero ahora, una vez repartida en lotes el área no colonizada, apenas se puede hablar de una línea fronteriza. Por lo tanto, la discusión de su extensión, de su desplazamiento hacia el Oeste, etc., ya no puede tener cabida en los informes referentes al censo." Esta breve declaración oficial señala el fin de un gran movimiento histórico. Hasta hoy, la historia norteamericana ha sido sobre todo la de la colonización del Gran Oeste. La existencia de una zona de tierras libres, su continua recesión y el avance de la colonización hacia el Oeste, explican el desenvolvimiento de la nación norteamericana. Detrás de las instituciones y de las modificaciones y formas constitucionales se encuentran las fuerzas que dan vida a todos los organismos, modelándolos para enfrentarse a condiciones cambiantes. La peculiaridad de las instituciones norteamericanas radica en el hecho de que se han visto obligadas a adaptarse a los cambios de un pueblo en expansión, a los cambios que conlleva el cruce de un continente, la conquista de tierras salvajes y el paso en cada zona de unas condiciones económicas y políticas primitivas, a las complejidades de la vida ciudadana. Calhoun decía en 1817: "Somos grandes y -casi temo decirlo- ¡crecemos rápidamente!" Con esas palabras declinaba la característica distintiva de la vida norteamericana. Todos los pueblos manifiestan un desarrollo; la teoría política de los gérmenes ha sido suficientemente resaltada. Sin embargo, en el caso de la mayoría de las naciones, el desarrollo se ha producido en un área limitada y si la nación ha experimentado un proceso de expansión, ha encontrado en su camino a otros pueblos en fase evolutiva y los ha conquistado. Pero en el caso de los Estados Unidos nos encontramos con un fenómeno distinto. Centrando nuestra atención en la costa atlántica, vemos el habitual fenómeno de la evolución de las instituciones en una zona limitada, tales como el desarrollo del gobierno representativo, la diferenciación del simple gobierno colonial en organismos complejos y el paso desde la sociedad industrial primitiva, sin división de trabajo, a la civilización industrial de primer orden. Pero además, observamos una repetición del proceso de evolución en cada zona occidental alcanzada por el proceso de expansión. Así pues, el desarrollo norteamericano no ha representado un mero adelanto a lo largo de una línea única, sino un retorno a condiciones primitivas 
en una linea fronteriza continuamente en movimiento de avance, con un nuevo desarrollo zonal. El desarrollo social norteamericano ha recomenzado continuamente en la frontera. Ese renacimiento perenne, esa fluidez de la vida norteamericana, esa expansión hacia el Oeste con sus nuevas oportunidades y su contacto ininterrumpido con la simplicidad de la sociedad primitiva, proporciona las fuerzas que dominan la idiosincrasia norteamericana. La verdadera mira en la historia de esta nación no es la costa atlántica, sino el Gran Oeste. Incluso la lucha por la abolición de la esclavitud, objeto exclusivo de la atención de tantos escritores, como el profesor von Holst, ocupa un papel destacado en la historia norteamericana precisamente por su conexión con la expansión hacia el Oeste.

En ese avance, la frontera es el borde exterior de la ola, el punto de contacto entre la barbarie y la civilización. Mucho se ha escrito sobre la frontera desde el punto de vista de la guerra y de la caza ahí desarrolladas, pero se ha pasado por alto la importancia que presenta para el economista y el historiador como campo de estudio serio.

La frontera norteamericana se diferencia claramente de la europea, que es una línea fronteriza fortificada que corre a través de territorios densamente poblados. Lo más importante de la frontera norteamericana es que se encuentra en el margen más cercano de las tierras abiertas a la expansión. En los informes del censo está considerada como el margen de una comunidad de colonos con una densidad de dos o más habitantes por milla cuadrada. El término es elástico, y para el objeto que nos proponemos no necesita ser definido con precisión. Consideraremos toda la franja fronteriza, incluyendo el país habitado por los indios y el limite externo del área colonizada de los informes del censo. Este ensayo no pretende tratar exhaustivamente el tema; aspira simplemente a llamar la atención hacia la frontera como campo de investigación fértil y a sugerir algunos de los problemas que surgen en relación con ella.

En el proceso de colonización de Norteamérica debemos observar cómo entró en el continente la vida europea y cómo este país modificó y desarrolló esa vida y afectó a Europa. Nuestra historia primitiva es el estudio del desenvolvimiento de los gérmenes europeos en el medio ambiente americano. Los investigadores de cuestiones institucionales han prestado demasiada atención a los orígenes germánicos y muy poca a los factores americanos. La frontera es la línea de norteamericanización más rápida y efectiva. La tierra virgen domina al colono. Llega vestido a la europea, viaja a la europea y europeas son su manera de pensar y las herramientas que utiliza. La tierra virgen lo saca del carro de ferrocarril y lo mete en la canoa de abedul. Le quita los trajes de la civilización y le pone la chamarra de cazador y los mocasines. Le hace vivir en la cabaña de troncos de los cherokees o de los iroqueses y construir en torno a ella una empalizada india. No pasa mucho tiempo sin que el colono siembre maíz y labre la tierra con un palo aguzado; lanza el grito de guerra y arranca el cuero cabelludo al estilo indio más ortodoxo. En una palabra, el medio ambiente de la frontera resulta al principio demasiado duro para el hombre blanco; debe aceptar las condiciones que le impone si no quiere 
perecer y por lo tanto se instala en los claros indios y sigue las pistas indias. Paulatinamente transforma la tierra salvaje, pero el resultado no es la vieja Europa, ni el simple desarrollo de los gérmenes germánicos ni un caso de reversión a la antigua marca germánica, sino el surgimiento de un nuevo producto que es americano. Al principio, la frontera era la costa atlántica. Era la frontera con Europa en un sentido muy real. Al moverse hacia el Oeste, la frontera se vuelve cada vez más norteamericana. Lo mismo que de sucesivas glaciaciones resultan morrenas terminales, cada frontera deja su huella, y cuando la región se convierte en zona colonizada, sigue participando de las características de la frontera. Así pues, el avance de la frontera significa un continuo alejamiento de la influencia de Europa, una firme progresión hacia la independencia según planteamientos norteamericanos. El estudio de ese avance y de los hombres que vivieron en tales condiciones, así como de los resultados económicos y políticos que produjo, equivale a estudiar la porción realmente norteamericana de nuestra historia.

En el transcurso del siglo XVII, la frontera fue subiendo por los ríos que desembocan en el Atlántico pasando por la fall line, ${ }^{1}$ convirtiendo la región junto al mar en zona colonizada. En la primera mitad del siglo Xvill tuvo lugar otro avance. Los traficantes siguieron a los indios delawares y shawnees hasta el Ohio a fines del primer cuarto de aquel siglo. En 1714, Spotswood, gobernador de Virginia, efectúo una expedición por el Blue Ridge. A finales del primer cuarto de siglo, escoceses-irlandeses y alemanes del $\mathrm{Pa}$ latinado avanzaron por el valle del Shenandoah hacia la parte occidental de Virginia y a lo largo de la región de las tierras bajas de las Carolinas. Los alemanes de la colonia de Nueva York llevaron la frontera por el Mohawk hasta German Flats. En Pennsylvania, el pueblo de Bedford indica el límite de colonización. Pronto se alzaron establecimientos en el New River, un tributario del Kanawha, y en las fuentes del Yadkin y del French Board. El rey intentó detener el avance en su proclama de 1763, al prohibir establecimientos más allá de las fuentes de los ríos que vierten en el Atlántico; en vano. En el periodo de la revolución, la frontera cruzaba los Alleghanies y entraba en Kentucky y en Tennessee, y se colonizó el curso superior del Ohio. Cuando en 1790 se hizo el primer censo, la zona colonizada continuamente estaba limitada por una línea que pasaba cerca de la costa de Maine, e incluía a Nueva Inglaterra excepto una porción de Vermont y Nueva Hampshire, a Nueva York a lo largo del Hudson y Mohawk hasta Schenectady, a Pennsylvania oriental y meridional, a Virginia, bastante más allá del valle del Shenandoah, y a las Carolinas y Georgia oriental. Pasada esa zona de colonización continua se encontraban las pequeñas áreas colonizadas de Kentucky y Tennessee y del Ohio, con montañas que las separaban de la zona atlántica, dando un nuevo e importante carácter a la frontera. El aislamiento de la región aumentó sus tendencias peculiarmente norteamericanas y la necesidad de crear trasportes para enlazarla con el Este dio lugar a importantes proyectos de mejoras internas, de las que nos ocuparemos más tarde. El "Oeste" comenzaba a

I Línea geográfica que indica el comienzo de una meseta. (N. del T.) 
desarrollarse como región con conciencia de sí misma.

Década tras década se fueron produciendo avances de la frontera. En el censo de 1820 el área colonizada incluia a Ohio, el sur de Indiana e Illinois, el sudeste de Missouri y alrededor de la mitad de Luisiana. Esta zona colonizada habia rodeado territorios indios y el control de las tribus que los ocupaban llegó a despertar el interés político. La región fronteriza de entonces se extendía a lo largo de los Grandes Lagos, donde la Astor's American Fur Company, ${ }^{2}$ comerciaba con los indios, y al otro lado del Mississippi, donde los que comerciaban con los indios extendieron su actividad incluso hasta las Montañas Rocallosas; también Florida presentaba una situación de frontera. La región del río Mississippi era escenario de una típica colonización fronteriza.

El inicio de la navegación a vapor en aguas occidentales, la apertura del canal del Erie y la extensión del cultivo del algodón hacia el Oeste añadieron en aquel periodo cinco estados fronterizos a la Unión. Grund escribía en 1836: "Resulta evidente, por lo tanto, que la disposición general de los norteamericanos a emigrar hacia las tierras vírgenes del Oeste para ampliar su dominio sobre la naturaleza inanimada, es el resultado real de un poder de expansión inherente en ellos y que, al mover sin interrupción a todas las clases de la sociedad, lanza constantemente una gran parte de la población total hacia los confines externos del estado con objeto de ganar espacio para su desarrollo. Apenas se ha constituido un nuevo estado o territorio cuando vuelve a manifestarse el mismo principio, dando lugar a otra emigración; y así sucesivamente, hasta que, al fin, una barrera física detiene el avance."

A mediados de aquel siglo, la frontera indicada por el actual limite oriental del territorio indio, Nebraska y Kansas, señalaba el confin con el país indio. Minnesota y Wisconsin todavía presentaban condiciones de frontera, ${ }^{3}$ pero en aquel tiempo la frontera característica se encuentra en California, donde los hallazgos de oro habian producido una oleada repentina de mineros aventureros, en Oregón y en los establecimientos de Utah. Del mismo modo que la frontera había saltado sobre los Alleghanies, ahora sobrepasaba las Grandes Llanuras y las Montañas Rocallosas e igual que el avance de los hombres de la frontera habia provocado importantes problemas de transporte y de mejoras internas, así también los colonos situados más allá de las Montañas Rocallosas requerían medios de comunicación con el Este. Cuando se establecieron esos medios se produjo la colonización de las Grandes Llanuras y el desarrollo de una nueva clase de vida en la frontera. Los ferrocarriles, a los que favorecieron las concesiones de tierras, arrojaron una creciente oleada de inmigrantes hacia el Lejano Oeste. El ejército de los Estados Unidos sostuvo una serie de guerras con los indios en Minnesota, Dakota y en el territorio indio.

\footnotetext{
2 Un colaborador del The Home Missionary (1850) ..., al referirse a las condiciones existentes en Wisconsin, exclama: "Miren esto, fijense en esto, gentes del ilustrado Este. ¡Qué ejemplo venía de la frontera misma de la civilización!" Pero uno de los misioneros escribe: "Dentro de unos pocos años, Wisconsin ya no será considerado Oeste, o, como avanzada de la civilización, más de lo que ahora es el occidente de Nueva York o la Reserva occidental."

${ }^{3}$ Se trataba de una compañia peletera. (N. del T.)
} 
En 1880 , la zona colonizada había alcanzado el norte de Michigan, Wisconsin y Minnesota, los ríos de Dakota y la región de Black Hills, y ascendía por los ríos de Kansas y de Nebraska. El desarrollo minero en Colorado había dado lugar a establecimientos fronterizos aislados y Montana e Idaho recibían colonos. La frontera se encontraba en esos campos mineros y en los ranchos de las Grandes Llanuras. El superintendente del censo de 1890 manifiesta, como dijimos antes, que los establecimientos del Oeste estaban tan diseminados por toda la región que ya no podía hablarse de una línea fronteriza.

En esas fronteras sucesivas encontramos límites naturales que han servido para señalar y modificar las características de las fronteras, es decir, la fall line; las montañas de los Alleghanies; el Mississippi; el Missouri, cuya dirección de norte a sur es manifiesta; las tierras áridas, aproximadamente en el meridiano 99; y las Montañas Rocallosas. La fall line constituyó la frontera en el siglo XVII; los Alleghanies, en el XVIII; el Mississippi, en el primer cuarto del XIX; el Missouri, en la mitad de ese mismo siglo (sin contar el desplazamiento hacia California) y el cinturón de las Montañas Rocallosas y la zona árida, es la frontera actual. Cada una de ellas se consiguió mediante una serie de guerras contra los indios.

En la frontera atlántica se pueden estudiar los gérmenes de procesos repetidos en cada una de las fronteras sucesivas. Vemos que la compleja vida europea se precipita bruscamente hacia la simplicidad de las circunstancias primitivas debido a las condiciones de vida en las tierras vírgenes. La primera frontera tuvo que hacer frente al problema indio, al de la disposición de las tierras públicas, de los medios de comunicación con establecimientos más antiguos, de la extensión de la organización política y de la actividad religiosa y educativa. La solución de estas cuestiones y de otras similares en una frontera servía de guía para la próxima. El investigador norteamericano no necesita remontarse a los "pequeños y modestos ayuntamientos de Schleswig" para ejemplificar la ley de continuidad y desarrollo. Por ejemplo, puede estudiar el origen de nuestros sistemas de propiedad de la tierra en el sistema de propiedad colonial; podrá observar cómo fue desarrollándose dicho sistema con la adaptación de los estatutos a las costumbres de las fronteras sucesivas. Puede ver como la experiencia minera en las regiones de yacimientos de plomo de Wisconsin, Illinois e Iowa fue aplicada a las leyes mineras de las Sierras, y cómo ha sido probada nuestra política respecto a los indios en las sucesivas fronteras. Cada serie de nuevos estados ha encontrado material para sus constituciones en los más antiguos. Cada frontera ha contribuido en forma similar al carácter norteamericano, como expondremos más adelante.

Pero a pesar de todas esas analogías, hay diferencias esenciales debidas a dos elementos: el lugar y el tiempo. Es evidente que la frontera agrícola del valle del Mississippi presenta condiciones diferentes a las imperantes en la frontera minera de las Montañas Rocallosas. La frontera alcanzada por el Pacific Railroad, objeto de levantamientos topográficos rectangulares, protegida por el ejército de los Estados Unidos y abastecida por la llegada diaria de emigrantes, avanza con mayor rapidez y de un modo distinto que 
-la frontera a la que se llega en la canoa de abedul o con caballo de carga. El geólogo traza pacientemente las orillas de mares antiguos, hace planos de las extensiones que abarcaron y compara las viejas con las nuevas. Sería una labor digna del historiador señalar esas diversas fronteras y compararlas detalladamente unas con otras. Así no sólo se obtendría una concepción más adecuada del desarrollo y las características norteamericanas sino también datos de incalculable valor para la historia de la sociedad.

El economista italiano Loria ha aconsejado el estudio de la vida colonial como una ayuda para comprender las fases del desarrollo europeo, afirmando que el establecimiento colonial es a la ciencia económica lo que la montaña es a la geología cuando revela las estratificaciones primitivas. Norteamérica -dice- posee la clave del enigma histórico que Europa ha buscado en vano durante siglos, y el país que no tiene historia revela luminosamente el curso de la historia universal. Esas palabras tienen mucho de verdad. Los Estados Unidos se presentan como una página inmensa en la historia de la sociedad. Cuando leemos línea tras línea, de este a oeste, esa página continental, encontramos el testimonio de una evolución social. Empieza con el indio y el cazador; sigue explicando la desintegración de la barbarie mediante la aparición del comerciante, que es quien encuentra el sendero de la civilización; leemos los anales de la fase pastoril en la vida del rancho; la explotación del suelo mediante el cultivo sin rotación del maíz y del trigo en comunidades agrícolas diseminadas; el cultivo intensivo en los establecimientos agrícolas más densamente poblados y, por último, la organización industrial en las ciudades y las fábricas. Es una página familiar para todo aquél que estudia las estadísticas de los censos, pero ha sido poco utilizada por nuestros historiadores. Especialmente en los estados del Este, esa página es como un palimpsesto. Lo que es ahora un estado industrial fue durante la década anterior una zona de cultivos intensivos. Antes habia sido una zona triguera y anteriormente la "pradera", que atraía al ganadero. Por ejemplo Wisconsin, que se desarrolla como estado industrial, cuenta con diversos intereses agrícolas. Pero antes se dedicaba casi exclusivamente al cultivo de cereales, como lo hace hoy Dakota del Norte.

Cada una de esas regiones ha influido en nuestra historia política y económica; la evolución de cada una de ellas a una fase más elevada ha traido como consecuencia transformaciones políticas. Pero ¿qué historiador de la Constitución ha intentado interpretar adecuadamente los hechos políticos a la luz de esas áreas y esos cambios sociales?

En la frontera atlántica habitaban pescadores, traficantes de pieles, mineros, ganaderos y agricultores. Con excepción de la pesca, cada industria se sentía impulsada hacia el Oeste por una irresistible atracción. Cada una de ellas atravesó el continente en oleadas sucesivas. Detengámonos en Cumberland Gap y contemplemos la procesión de la civilización, que marcha en fila india -el búfalo tras la pista que lleva a las fuentes de agua salada, el indio, el traficante de pieles y cazador, el ganadero, el colono agricultor- y la frontera ha pasado de largo. Situémonos un siglo después en South Pass, en las Rocallosas, y veremos la misma procesión con intervalos mayores entre sus elementos. La velocidad desigual del 
avance nos obliga a distinguir entre la frontera del traficante, del ranchero, del minero y del agricultor. Cuando las minas y los cercados para las vacas estaban todavía cerca de la fall line las caravanas de mulas de los traficantes dejaban oír sus campanillas a través de los Alleghanies, y los franceses de los Grandes Lagos fortificaban sus puestos, alarmados por la canoa de abedul del comerciante británico. Cuando los tramperos escalaron las Rocallosas el agricultor estaba todavía cerca de la desembocadura del Missouri.

¿Por qué atravesó tan rápidamente el continente el que comerciaba con los indios? ¿Qué efectos trajo la frontera del traficante? El desarrollo del comercio fue contemporáneo al descubrimiento de América. Los escandinavos, Vespucio, Verrazano, Hudson, John Smith, todos traficaron en pieles. Los peregrinos de Plymouth se establecieron en tierras indias productoras de maiz y su primer cargamento estaba constituido por pieles de castor y madera. Los documentos que tratan de las diversas colonias de Nueva Inglaterra muestran la continuidad con que los traficantes exploraron las tierras vírgenes. $\mathrm{Y}$ esto puede aplicarse, con mayor razón, al resto de las colonias. A todo lo largo de la costa, desde Maine a Georgia, el tráfico con los indios abrió el curso de los ríos. Constantemente, el comerciante se adentraba en el Oeste, siguiendo las viejas rutas del comercio francés. El Ohio, los Grandes Lagos, el Mississippi, el Missouri y el Platte -rutas del avance hacia el Oeste- fueron recorridos por los traficantes. Descubrieron los pasos de las Montañas Rocallosas y guiaron a Lewis y a Clark, ${ }^{4}$ a Frémont y a Bidwell. La explicación de la rapidez de esa marcha se relaciona con los efectos de los comerciantes sobre los indios. El puesto comercial dejaba a las desarmadas tribus a merced de aquellas que habian comprado armas de fuego: verdad que los indios iroqueses escribieron con sangre, y por ellos las tribus remotas y menos visitadas eran las que más ansiaban recibir al trafičante. "Los salvajes -escribía La Salle- nos hacen objeto de más atenciones a los franceses que a sus propios hijos pues sólo de nosotros pueden obtener armas y mercancías". Esto explica el poderío del traficante y la rapidez de su avance. Así entraron en las tierras vírgenes las fuerzas desintegradoras de la civilización. Cada valle y cada pista del indio se convirtió en una fisura en los sociedad india, de tal manera que esa sociedad fue adquiriendo la estructura de un panal. Mucho antes de que aparecieran en escena los colonos dedicados a la agricultura, la primitiva vida india había dejado de existir. Los campesinos se encontraron con indios armados de fusiles. La frontera comercial, al mismo tiempo que minaba con firmeza el poder de los indios haciendo finalmente a las tribus dependientes de los blancos, debido a la venta de armas de fuego aumentó el poder de resistencia del indio contra la frontera agrícola. La frontera comercial dominaba la colonización francesa y la frontera agrícola la inglesa. Había un antagonismo entre las dos fronteras como entre las dos naciones. Duquesne decía a los iroqueses: ¿No saben la diferencia que existe entre el rey

\footnotetext{
${ }^{4} \mathrm{Si}$ bien Lewis y Clark fueron los primeros en explorar la ruta que va del Missouri al Columbia.
} 
de Inglaterra y el rey de Francia? Vayan a ver los fuertes que nuestro rey ha establecido y verán que pueden cazar junto a sus muros. Se han levantado para protegerlos en los lugares que frecuentan. Los ingleses, al contrario, apenas entran en posesión de un lugar, acaban con la caza. La selva cae ante ellos conforme avanzan y la tierra queda desnuda, de tal manera que ni siquiera pueden ustedes encontrar en ella algo con qué construir un albergue para pasar la noche.

$Y$, sin embargo, a pesar de esta oposición entre ios intereses del traficante y del agricultor, el comercio con los indios preparó el camino de la civilización. La pista del búfalo se convirtió en pista del indio y después en el sendero del traficante; estos senderos se convirtieron en caminos y los caminos en caminos de peaje, y a su vez éstos fueron transformados en vías de ferrocarril. El mismo origen tienen los ferrocarriles del Sur, del Lejano Oeste y del Dominio del Canadá. Los puestos comerciales a que conducían esas pistas estaban situados en pueblos indios asentados en lugares impuestos por la naturaleza: dominaban el sistema hidrográfico del país y son ahora ciudades como Albany, Pittsburgh, Detroit, Chicago, St. Louis, Council Bluffs y Kansas City. Así pues, la civilización ha seguido, en Norteamérica, las arterias geológicas, derramando por ellas una marea cada vez más fuerte, de forma que los tenues senderos trazados por los aborígenes se han ensanchado y entrecruzado hasta formar los complejos laberintos de las rutas comerciales modernas; cruzan las tierras vírgenes rutas de civilización cada vez más numerosas. Da la impresión del crecimiento continuo de un complicado sistema nervioso en un continente primitivamente sencillo e inerte. Si queremos comprender por qué somos hoy una nación y no una colección de estados aislados, deberemos estudiar esa consolidación económica y social del país. Quien se dedique a investigar la teoría de la evolución encontrará en ese desarrollo temas de estudio.

El efecto de la frontera india es importante como factor de consolidación en nuestra historia. Desde fines del siglo XVII se celébraron varios congresos intercoloniales para discutir la forma de tratar a los indios y establecer medidas de defensa comunes. El individualismo era más intenso en las colonias que no tenian frontera india, frontera que se extendía a lo largo de los límites occidentales como un lazo de unión. El indio era un peligro común que exigía unidad en la acción. La más famosa de esas reuniones fue el congreso de Albany, de 1754, convocado para tratar con las Seis Naciones y para estudiar planes de unión. Echando apenas una ojeada al plan propuesto por el congreso nos daremos cuenta de la importancia de la frontera. El consejo general y los funcionarios tenían, principalmente, los poderes de decidir si se mantenía la paz o se iba a la guerra contra los indios, de regularizar el comercio con ellos, de comprar sus tierras, y de crear y gobernar nuevos establecimientos, como medida de seguridad en relación a los indios. Es evidente que las tendencias unificadoras del periodo revolucionario fueron favorecidas por la cooperación previa en la regulación de la frontera. En este sentido, se puede considerar la importancia de la frontera, desde entonces hasta ahora, como escuela de adiestramiento militar que mantenía vivo el poder de resistencia a la agresión y desarrollaba las rudas y esforzadas cualidades del hombre de la frontera. 
Es imposible trazar las otras fronteras que cruzaron el continente dentro de los límites de este ensayo. Los viajeros del siglo XVIII pudieron ver cercados de vacas entre los cañaverales y pasturas del Sur, y los vaqueros llevaban sus manadas a Charleston, Filadelfia y Nueva York. Al terminar la guerra de 1812, los vaqueros se encontraron con hatos de mil cabezas y con piaras de cerdos que desde el interior de Ohio iban a Pennsylvania a engordar para ser presentados en el mercado de Filadelfia. Las praderas de las Grandes Llanuras, con sus ranchos, sus vaqueros y su vida nómada, son cosas de ayer y de hoy. La experiencia de los cercados de vacas de Carolina sirvió de guía a los rancheros de Texas. Un elemento que favorece la rápida extensión de la frontera del ranchero es el hecho de que en un país remoto carente de medios de transporte, la producción debe ser limitada o capaz de transportarse por sí misma, pudiendo el ganadero llevar entonces fácilmente sus productos al mercado. Convendria estudiar el efecto de esos grandes ranchos sobre la historia agraria posterior de las localidades en que existieron.

Los mapas incluidos en los informes del censo ponen de manifiesto un avance desigual de la frontera del agricultor, con avanzadas de colonización adelante y penetraciones en las tierras vírgenes. Esto se debe a la resistencia opuesta por los indios, a la situación de los valles y los pasos de los rios y a la desigual fuerza de atracciones de los centros fronterizos. Entre los centros importantes de atracción podemos mencionar las tierras fértiles y bien situadas, los manantiales de agua salada, las minas y los puestos militares.

El puesto militar fronterizo, que protegía a los colonos contra los indios, actuaba también como cuña de penetración en el país indio y fue un núcleo para la colonización. A este respecto, debe hacerse mención de las expediciones militares y de exploración organizadas por el gobierno para determinar las lineas de colonización. Las expediciones más importantes tienen mucho que agradecer a los primeros exploradores, a los guías indios, a los comerciantes y a los tramperos, así como a los viajeros franceses, que eran parte inevitable de las expediciones gubernamentales desde los tiempos de Lewis y de Clark. Cada expedición era un resumen de los factores anteriores en el avance hacia el Oeste.

En una interesante monografía, Victor Hehn ha seguido el efecto de la sal sobre el desarrollo de la Europa antigua, poniendo de relieve cómo afectó a las líneas de colonización y a la forma de administración. Un estudio similar podría hacerse con respecto a los manantiales de agua salada de los Estados Unidos. Los primeros colonos estaban ligados a la costa por la necesidad de sal, sin la cuál no podían conservar sus alimentos ni vivir sin molestias. En 1752, el obispo Spangenburg escribia, refiriéndose a una colonia para la que estaba buscando tierras en Carolina del Norte: "Requerirán sal y otras cosas necesarias que no podrán fabricar ni cultivar. Tendrán que ir a Charleston, que está a 300 millas... O bien, deberán ir a Boling's Point en Virginia, sobre un brazo del James y que también está a 300 millas de aquí... O tendrán que ir a Roanoke abajo -no sé por cuantas millas- hasta el lugar a donde se lleva la sal del Cape Fear'. Esto puede servirnos como ejemplo típico. Era esencial hacer una peregrinación anual a la costa en 
busca de sal. Todos los años, después de la siembra, los primeros colonos enviaban sus recuas a la costa con rebaños o pieles y raíces de ginseng. Esto constituyó una importante influencia educativa, ya que era casi el único medio por el que los colonos se enteraban de lo que ocurría en el Este. Pero cuando se descubrieron los manantiales de agua salada del Kanawha, del Holston y de Kentucky, y en la zona central del estado de Nueva York, el Oeste comenzó a liberarse de la dependencia de la costa. El efecto del descubrimiento de esos manantiales fue lo que hizo posible, en parte, que los colonos pudieran cruzar las montañas.

Desde el momento en que las montañas se interpusieron entre los primeros colonos y la costa del mar, surgió un nuevo orden de norteamericanismo. El Oeste y el Este comenzaron a perder contacto. Los establecimientos instalados entre el mar y las montañas mantenian relación con la retaguardia y conservaban una cierta solidaridad. Pero el hombre situado al otro lado de las montañas fue haciéndose cada vez más independiente. El Este adoptó un punto de vista restrictivo acerca del avance norteamericano y casi perdió a aquellos hombres. La historia de Kentucky y de Tennessee presenta abundantes testimonios de lo cierta que resulta tal afirmación. El Este inició sus intentos de cercar y limitar la expansión hacia el Oeste. Aunque Webster declarase que los Alleghanies no entraban en su política, constituían un sólido factor en la política general.

La explotación de animales salvajes impulsó al cazador y al traficante hacia el Oeste, la explotación de los pastos produjo el mismo efecto en el ranchero, y la explotación de las tierras vírgenes de los valles de los rios y de las praderas atrajo al agricultor. La tierra fértil ha sido el elemento de atracción más frecuente de la frontera del agricultor. El hambre de tierras que sentian los habitantes de Virginia los impulsó a seguir los ríos hasta Carolina en los primeros tiempos coloniales; la búsqueda de tierras llevó a los hombres de Massachussetts a Pennsylvania y a Nueva York. Conforme iban siendo ocupadas las tierras orientales, la emigración las dejaba atrás en su camino hacia el Oeste. Daniel Boone, el gran backwoodsman, ${ }^{5}$ que fue a la vez cazador, traficante, ganadero, agricultor y agrimensor, al enterarse, probablemente por los traficantes, de la fertilidad de las tierras del curso alto del Yadkin, donde solian descansar tales traficantes en su camino hacia el territorio indio, abandonó junto con su padre el hogar de Pennsylvania y, siguiendo el camino de Great Valley, llegó a aquel río. Al comunicarle un traficante la gran riqueza en caza y pastos que poseía Kentucky, abrió los caminos de aquella región a los agricultores. De allí pasó a la frontera de Missouri, donde su establecimiento constituyó como un hito de la frontera. Allí ayudó también a abrir el camino de la civilización, descubriendo manantiales de agua salada, pistas y tierras cultivables. Su hijo fue uno de los primeros tramperos que llegaron a los pasos de las Montañas Rocallosas y se dice que él y sus compañeros fueron los primeros que acamparon en el actual emplazamiento de Denver. Su nieto, el coronel A. J. Boone, de Colorado, gozó de gran prestigio entre los

\footnotetext{
${ }^{5}$ Habitante de regiones remotas y sin cultivar. (N. del T.)
} 
indios de las Montañas Rocallosas, y fue nombrado agente del gobierno. La madre de Kit Carson era una Boone. El avance del backwoodsman a través del.continente está compendiado en la familia Boone.

El avance de los agricultores se produjo en una serie de oleadas sucesivas. En la Nueva guia para el Oeste, de Peck, publicada en Boston en 1837, se lee este sugerente pasaje:

Por lo general en todos los establecimientos de colonos en el Oeste se han sucedido tres promociones, una después de otra, como las olas del océano. Viene, en primer lugar, el pionero, que depende, para la subsistencia de su familia, principalmente del crecimiento natural de la vegetación, esto es, de la pradera y del producto de la caza.

Sus aperos agrícolas son toscos, generalmente construidos por él mismo, y sus esfuerzos se encaminan sobre todo al cultivo del maíz y a mantener un rudimentario sembrado de hortalizas para recolectar coles, frijoles, maíz para asar las mazorcas, pepinos y papas. Le basta con una cabaña de troncos, y a veces con un establo, un granero, un campo de una docena de acres y el cercado o vallado de madera. No le preocupa si alguna vez llegará a ser propietario del terreno donde se ha asentado. Lo ocupa de momento, no paga arriendo y se siente tan independiente como un verdadero terrateniente. Con un caballo, una vaca y uno o dos sementales porcinos, se instala en el bosque con su familia y llega a ser el fundador de un nuevo condado, quizá de un estado. Construye su cabaña, reúne alrededor suyo unas cuantas familias de gustos y costumbres similares a los suyos y permanece alli hasta que la zona está parcialmente colonizada y la caza va escaseando, o bien -y es el caso más frecuente- hasta que los vecinos se hacen demasiado numerosos, los caminos, puentes y campos empiezan a fastidiarle y siente la falta de espacio vital. La ley de prioridad le permite vender su cabaña y su campo de maíz a la nueva promoción de emigrantes y, para emplear sus propias imágenes, "busca un nuevo camino en el bosque", "se marcha para adquirir algo nuevo" y emigra a Arkansas o a Texas para repetir el proceso.

La siguiente promoción de emigrantes compra las tierras, amplía sus campos, abre caminos, tiende rudimentarios puentes sobre los cursos de agua, construye casas de troncos descortezados con ventanas de cristal y chimeneas de ladrillo o piedra. A veces planta huertas, construye molinos, escuelas, juzgados, etc. Todo eso presenta el cuadro y la forma de una vida sencilla, frugal y civilizada.

Llega otra oleada. Vienen los hombres de capital y de empresa. El colono está dispuesto a vender, aprovechándose de la subida en el valor de las propiedades, y a lanzarse hacia el interior para convertirse, él también, en hombre de capital y de empresa. El pequeño pueblo se convierte en una gran población o en ciudad; pueden verse importantes edificios de ladrillo, amplios campos cultivados, huertos, jardines, universidades e iglesias. Están en boga los paños finos de lana, las sedas, los sombreros de paja de ala ancha, los velos y toda clase de refinamientos, lujos, elegancias, frivolidades y caprichos de la moda. Así pues, una oleada tras otra va rodando hacia el Oeste; el verdadero El Dorado siempre parece estar más adelante.

Una parte de los componentes de las dos primeras promociones permanece fija en medio del movimiento general, mejora sus costumbres y condiciones y se eleva en la escala de la sociedad.

Quien escribe estas líneas ha viajado mucho como parte de la primera promoción, entre los verdaderos pioneros. Ha vivido muchos años en relación con la segunda categoria; y ahora, la tercera oleada se está extendiendo sobre grandes distritos de Indiana, Illinois y Mis- 
souri. La emigración ha llegado a ser casi un hábito en el Oeste. Pueden verse cientos de hombres menores de cincuenta años, que se han establecido en sitios nuevos, cuatro, cinco o seis veces. Venderlo todo y marcharse unos cuantos centenares de millas más allá es parte de la variedad de vida y costumbres de las regiones remotas y sin cultivar.

Aparte de aquellos campesinos pioneros impulsados solamente por amor a la aventura, el avance del campesino más estable es fácil de comprender. Evidentemente el inmigrante se sentia atraído por las tierras baratas de la frontera, e incluso el agricultor nativo sentía fuertemente su influencia. Año tras año los campesinos que vivían de un suelo cuyo rendimiento disminuía por no rotar los cultivos, veían cómo se les ofrecían, a precios nominales, tierras vírgenes de la frontera. Sus crecientes familias exigían más tierras, que eran caras. La competencia de las tierras de las praderas, sin agotar, baratas y de fácil labranza, impulsó al campesino o a irse al Oeste y continuar agotando el suelo de una nueva frontera, o a adoptar el cultivo intensivo. Así, el censo de 1890 indica que en el noroeste habia muchos condados con un descenso de población absoluto o relativo. Aquellos estados habian estado enviando campesinos para adelantar la frontera en las llanuras y habían empezado a practicar el cultivo intensivo y a dedicarse a la industria. Una década antes, se había observado la misma fase de transición en Ohio. La demanda de tierras y el amor a la libertad favorecida por las tierras vírgenes adelantaba cada vez más la frontera.

Una vez esbozados a grandes rasgos las diferentes clases de fronteras y sus formas de avance, especialmente desde el punto de vista de la frontera misma, vamos a ocuparnos de la influencia que ejerció sobre el Este y sobre el Viejo Mundo. Sólo tengo tiempo para hacer una rápida enumeración de algunos de los efectos más notables.

Primeramente, vemos que la frontera promovió la formación de una nacionalidad compleja en el pueblo norteamericano. La costa era preponderantemente inglesa, pero las posteriores oleadas de inmigración continental se dirigieron rápidamente hacia las tierras libres. Así sucedió desde los primeros tiempos de la colonia. Los escoceses-irlandeses y los alemanes del Palatinado o los holandeses de Pennsylvania, constituían el elemento dominante entre los habitantes de la frontera colonial. Con ellos figuraban también los siervos escriturados o los redimidos quienes, al expirar su tiempo de servidumbre, pasaban a la frontera. Spotswood, el gobernador de Virginia, escribía en 1717: "Los habitantes de nuestras fronteras se componen, generalmente, de personas que han sido trasladadas hasta aquí como siervos y que, una vez cumplido su tiempo de servicio, se establecen donde hay tierras desocupadas que pueden producir lo necesario para vivir con poco trabajo". Casi ninguno de estos siervos redimidos era de origen inglés. En el crisol de la frontera los inmigrantes se americanizaban, se liberaban y se fundían en una raza mixta, que no era inglesa ni por la nacionalidad ni por sus características. $Y$ el proceso ha continuado desde los primeros tiempos hasta los nuestros. Burke y .otros escritores de mediados del siglo xvill creían que Pennsylvania estaba amenazada por el peligro de ser totalmente extranjera en idioma, cos- 
tumbres e incluso quizá en inclinaciones. Sólo en la frontera del Sur eran menos importantes los elementos alemanes y escocesesirlandeses. A mediados del siglo xIX el elemento alemán era de tal importancia en Wisconsin que eminentes publicistas consideraron la creación, a partir de esa comunidad, de un estado germánico por medio de la concentración de los colonos alemanes. Estos ejemplos deben ponernos en guardia contra la errónea interpretación de que por el hecho de que en los Estados Unidos se hable inglés el origen de la población es asimismo inglés.

El avance de la frontera disminuyó nuestra dependencia de Inglaterra también en otro aspecto. La costa, especialmente la del Sur, carecía de industrias diversificadas y dependía de ese país para el grueso de sus abastecimientos. El Sur dependía incluso de las colonias del Norte en articulos alimenticios. El gobernador Glenn, de Carolina del Sur, escribe a mediados del siglo Xvill: "Nuestro comercio con Nueva York y Filadelfia se hacía de tal suerte que absorbia toda la moneda y todos los billetes de banco que podiamos obtener de otras fuentes. Lo gastábamos para adquirir pan, harina, cerveza, jamón, tocino y otros productos de aquellas ciudades. En cambio ahora, todas esas cosas, excepto la cerveza, se empiezan a producir en nuestras comunidades, donde se han establecido alemanes muy trabajadores y prósperos. Esto, sin duda, disminuye el número de embarques y nuestra presencia comercial, pero está muy lejos de constituir un perjuicio para nosotros." No pasó mucho tiempo sin que la frontera crease demanda para los comerciantes. Conforme Inglaterra se iba retirando de la costa, le era cada vez menos posible enviar sus abastecimientos directamente al consumidor y llevarse las cose- chas de productos básicos, que empezaron a dejar su lugar durante algún tiempo a una agricultura diversificada. El efecto de esta fase de la acción de la frontera sobre la región norteña puede comprenderse si pensamos que el avance de la frontera hizo que ciudades costeras como Boston, Nueva York y Baltimore rivalizaran por conseguir lo que Washington llamó "el extenso y valioso comercio de un imperio naciente".

La legislación que más desarrolló los poderes del gobierno nacional y desempeñó el papel principal en su actividad, fue condicionada por la frontera. Los escritores se han ocupado de las cuestiones de la tarifa, la tierra y las mejoras internas como de algo subsidiario a la cuestión de la esclavitud. Pero cuando se examina debidamente la historia norteamericana se observará que la cuestión de la esclavitud no es más que un incidente. En el lapso que va del final de la primera mitad del siglo XIX al final de la guerra civil, la esclavitud llegó a tener una importancia primordial, pero en modo alguno exclusiva y no justifica que el doctor von Holst (por citar un ejemplo) tratara una historia constitucional en su periodo de formación hasta 1828 , en sólo un volumen, dedicando en cambio seis principalmente a la historia de la esclavitud de 1828 a 1861, bajo el título Constitutional History of the United States. El desarrollo del nacionalismo y la evolución de las instituciones políticas norteamericanas dependian del avance de la frontera. Hasta un autor tan reciente como Rhodes en su History of the United States since the Compromise of 1850 ha tratado la legislación a que dio lugar el movimiento hacia el 
Oeste como un incidente dentro de la lucha contra la esclavitud.

Es ésa una perspectiva equivocada. El pionero necesitaba las mercancias de la costa, y por tanto empezó la gran serie de mejoras internas y la legislación ferroviaria con potentes efectos nacionalistas. Sobre las mejoras internas se produjeron grandes debates en los que se discutieron graves cuestiones constitucionales. En las votaciones intervinieron grupos regionales, lo cual es de profunda significación para el historiador. La interpretación amplia [de la ley] aumentaba conforme la nación se dirigia hacia el Oeste. Pero el Oeste no se contentaba con llevar el campo a la fábrica. Bajo la dirección de Clay - "Harry del Oeste"- se aprobaron tarifas protectoras, con la consigna de llevar la fábrica al campo. La disposición de las tierras públicas fue un tercer e importante objeto de la legislación nacional influida por la frontera.

Las tierras de dominio público han constituido una fuerza de profunda importancia en la nacionalización y en el desarrollo del gobierno. Los efectos de la lucha de los estados poseedores y no poseedores de tierras, y de la Ordenanza de 1787 , no necesitan discusión. Administrativamente, la frontera provocó algunas de las más ilustres y vigorosas actividades del gobierno general. La adquisición de Luisiana fue quizá el punto de cambio constitucional en la historia de la República, pues por un lado ofreció un nuevo terreno para la legislación nacional y por otro ocasionó el fin de la política de interpretación estricta. Pero la adquisición de Luisiana fue provocada por necesidades y demandas fronterizas. Conforme los estados fronterizos ingresaban en la Unión, crecía el poder nacional. El Sr. Lamar afirmó en un discurso con motivo del descubrimiento de un monumento a Calhoun: "En 1789 los estados fueron los creadores del gobierno federal; en 1861 el gobierno federal fue el creador de una gran parte de los estados".

Cuando consideramos el patrimonio público desde el punto de vista de la venta y de la disposición de las tierras públicas, nos encontramos nuevamente cara a cara con la frontera. La política de los Estados Unidos en lo referente a sus tierras presenta un agudo contraste con el sistema europeo de administración científica. Fueron inútiles los esfuerzos para hacer de esas tierras una fuente de ingresos y para negárselas a los emigrantes con objeto de hacer más compacta la colonización. Los celos y los temores del Este resultaron impotentes frente a las demandas de los hombres de la frontera. John Quincy Adams se vio obligado a confesar: "Ha fracasado mi sistema de administración que consistía en hacer del territorio nacional un fondo inagotable para mejoras internas progresivas e incesantes." La razón es obvia; no era un sistema de administración lo que precisaba el Oeste, sino tierras. Adams exponía la situación del modo siguiente: "Los esclavistas del Sur han comprado la cooperación del Oeste sobornándolo con tierras, abandonando a nuevos estados occidentales su parte en la propiedad pública y ayudándoles en su designio de apoderarse de todas esas tierras. Thomas Benton era el autor de este sistema que aspiraba a sustituir el sistema americano del señor Clay y a suplantar a éste como hombre de Estado preeminente del Oeste. El Sr. Clay, debido a su compromiso sobre la tarifa con el Sr. Calhoun, abandonó su sistema americano. Al mismo tiempo presentó un plan para distribuir entre todos los estados de la Unión los 
ingresos procedentes de la venta de las tierras públicas. Su proyecto de ley fue aprobado por ambas Cámaras, pero fue vetado por el presidente Jackson, quien en su mensaje anual de diciembre de 1832 recomendó formalmente que todas las tierras públicas fueran entregadas gratuita e individualmente a los aventureros y a los estados donde estaban situadas tales tierras."

"Ningún asunto -dijo Henry Clay- presentado ante este Congreso y quizá ante cualquiera de los anteriores, tiene tanta magnitud como el de las tierras públicas." Si consideramos los efectos a largo plazo de la política gubernamental de tierras, sobre los aspectos políticos, económicos y sociales de la vida norteamericana, estamos dispuestos a mostrarnos de acuerdo con él. Pero esa legislatura fue estructurada bajo el influjo de la frontera y bajo la dirección de estadistas del Oeste como Benton y Jackson. El senador Scott, de Indiana, dijo en 1841: "Considero que la ley de prioridad no hace sino consagrar la costumbre o derecho común de los colonos".

No es aventurado decir que la legislación referente a la tierra, a la tarifa y a las mejoras internas -el sistema americano del nacionalista partido Whig- estaba condicionada por las ideas y necesidades de la frontera. Pero no era solamente en la acción legislativa donde la frontera obraba contra el regionalismo de la costa. Las características sociales y económicas de la frontera iban contra el regionalismo. El hombre de la frontera presentaba una mayor semejanza con la región central que con cualquiera de las otras regiones. Pennsylvania había sido el vivero de la emigración fronteriza, y si bien había llevado a sus colonos a lo largo del Great Valley hasta el Oeste de Virginia y las Carolinas, la sociedad industrial de esos hombres de la frontera del Sur se parecia más a la de la región central que a la de la zona marítima del Sur, que después extendió su tipo industrial por todo el Sur.

La región central, a la que se entraba por el puerto de Nueva York, era una puerta abierta para toda Europa. La zona marítima del Sur estaba habitada por tipicos ingleses, modificados por un clima cálido y por el trabajo servil, que vivian como nobles en grandes plantaciones; Nueva Inglaterra fue la sede de un movimiento inglés especial: el puritanismo. La región central era menos inglesa que las demás. Contenía una amplia mezcla de nacionalidades, una sociedad diversificada, su sistema de gobierno local participaba del carácter urbano y rural, su vida económica era variada, las sectas religiosas numerosas. En suma, era una región intermedia entre Nueva Inglaterra y el Sur, entre el Este y el Oeste. Representaba esa nacionalidad compleja que presentan los Estados Unidos contemporáneos, esa yuxtaposición de grupos no ingleses que ocupaban un valle o una pequeña zona colonizada y que en su variedad presentaban reflejos del mapa de Europa. Era democrática y sin regionalismos, si es que no nacional; "agradable, tolerante y satisfecha"; arraigada fuertemente en la prosperidad material. Era algo típico de los Estados Unidos modernos. Era menos regionalista, no solamente porque estaba situada entre el Norte y el Sur, sino también porque no tenía barreras que separasen sus fronteras de su región colonizada, y con un sistema de enlaces acuáticos, la región central comunicaba al Este con el Oeste, así como al Norte con el Sur. Así llegó a ser una región 
típicamente norteamericana. Incluso el natural de Nueva Inglaterra, que estaba separado de la frontera por la región central, al detenerse en Nueva York o en Pennsylvania en su camino hacia el Oeste, perdía mucha de la agudeza de su regionalismo.

La difusión del cultivo del algodón en el interior del Sur terminó rompiendo el contraste que existía entre la región costera y el resto del estado, basando los intereses meridionales en la esclavitud. Antes de que el proceso revelase sus resultados, la parte occidental del Sur, que era afín a Penssylvania en estirpe, sociedad e industria, mostró tendencias a desertar de la fe de los padres, a favor de una legislación de mejoras internas y una actitud nacionalista. En la Convención de Virginia de 1829-30, convocada para revisar la constitución, el Sr. Leigh, representante de Chesterfield, uno de los condados costeros, declaró:

Una de las causas principales de descontento que llevaron a esta convención, la que ha tenido influencia más fuerte para destruir nuestra veneración por la obra de nuestros padres y la que nos ha enseñado a despreciar las ideas de Henry, Mason y Pendleton, haciéndonos perder el respeto a las autoridades constituidas del Estado, ha sido la pasión presuntuosa de llevar a cabo mejoras internas. Digo esto con perfecto conocimiento, porque lo han reconocido ante mí una y otra vez los hombres del Oeste. Y permítaseme que diga al representante de Albemarle (el Sr. Gordon) que otro objetivo principal de los que ponen en marcha la bola de la revolución, ha sido el de derribar la doctrina de los derechos de los estados, de la que Virginia ha sido el verdadero pilar, y quitar la barrera que ha puesto de por medio a la interferencia del gobierno federal en la misma obra de mejoras internas, reorganizando la legislatura de forma que también Virginia pueda ser uncida al carro federal.

Esta tendencia nacionalista del Oeste fue la que transformó la democracia de Jefferson en el republicanismo nacional de Monroe y en la democracia de Andrew Jackson. El Oeste de la guerra de 1812, el Oeste de Clay, Benton, Harrison y Andrew Jackson, separado por los estados centrales y por las montañas de las regiones costeras, sentía una simpatía peculiar por las tendencias nacionales. Sobre la corriente del Padre de las Aguas, el Norte y el Sur se encontraron y se mezclaron en una nación. La emigración interestatal proseguía ininterrumpidamente y era un proceso de fertilización entrecruzada de ideas e instituciones. La fiera lucha entre regiones en la frontera occidental por la cuestión de la esclavitud no disminuye la verdad de esa afirmación, sino que la prueba. La esclavitud era un rasgo regional que no quería desaparecer, pero en el Oeste no pudo seguir siendo regional. El más grande de los hombres de la frontera declaró: "Creo que este gobierno no puede permanecer indefinidamente mitad esclavista y mitad libre. Habrá de decidirse por una cosa o por la otra." Nada trabaja tanto a favor del nacionalismo como las relaciones dentro de la nación. La movilidad de la población da muerte al localismo y la frontera occidental influía irresistiblemente sobre la población no establecida. El efecto repercutió desde la frontera y afectó profundamente a la costa del Atlántico e incluso al Viejo Mundo.

Pero el efecto más importante de la frontera ha sido haber fomentado la democracia tanto aquí como en Europa. Como ya se 
ha indicado, la frontera produce individualismo. Las tierras vírgenes empujan a la sociedad compleja hacia una especie de organización primitiva basada en la familia. La tendencia es antisocial. Produce antipatía contra toda forma de control, en especial si es directo. El recaudador de impuestos es visto como un representante de la opresión. El profesor Osgood, en un acertado artículo, ha indicado que las condiciones de frontera prevalecientes en las colonias son factores importantes para la explicación de la Revolución norteamericana, en la que la libertad individual se confundió algunas veces con la ausencia de todo gobierno efectivo. Las mismas condiciones ayudan a explicar la dificultad de instituir un gobierno fuerte en el periodo de la confederación. El individualismo de la frontera ha fomentado la democracia desde el principio.

Los estados fronterizos que entraron en la Unión en el primer cuarto de siglo de su existencia trajeron con ellos el sufragio democrático y produjeron reacciones de la mayor importancia sobre los estados más antiguos cuya población era atraída por aquéllos. Llegó a ser esencial una ampliación del derecho de voto. Fue el Nueva York occidental el que forzó una extensión del sufragio en la convención constitucional de aquel estado de 1821 ; y fue la Virginia occidental la que obligó a la región maritima a incluir disposiciones más liberales sobre el sufragio en la constitución elaborada en 1830 y a dar a la región fronteriza una representación más proporcionada respecto a la aristocracia de la costa. El ascenso de la democracia como fuerza efectiva de la nación se produjo con la preponderancia occidental bajo Jackson y William Henry Harrison, y significó el triunfo de la frontera con todos sus elementos, tanto buenos como malos. Un ejemplo interesante del tono de la democracia fronteriza en 1830 se encuentra en los debates de la convención de Virginia a que ya nos hemos referido. Un representante de Virginia occidental declaró:

Pero, señor, no es el crecimiento de población en el Oeste lo que debe temer este caballero. Es la energía que la brisa de la montaña y las costumbres del Oeste imparten a esos emigrantes. Se regeneran, quiero decir desde el punto de vista político, señor. Pronto se convierten en políticos activos y la diferencia que existe, señor, entre un político que habla y un político que actúa es inmensa. El Viejo Dominio ha sido celebrado durante mucho tiempo por haber producido grandes oradores, los más hábiles metafísicos de la política, hombres capaces de hilar fino en todas las oscuras cuestiones de economia política. Pero en casa, o cuando vuelven del Congreso, tienen negros que les abanican mientras duermen. Mas un estadista de Pennsylvania, de Nueva York, de Ohio o de Virginia occidental, aunque es muy inferior en lógica, metafísica y retórica con respecto de un viejo estadista virginiano, cuenta con la ventaja de que cuando vuelve a casa se quita el saco y se pone a labrar la tierra. Ello lo fortalece, señor, y hace que sus principios republicanos se conserven puros y sin contaminar.

Mientras exista tierra libre, existirá también la oportunidad de competencia, y el poder económico asegura el poder político. Pero la democracia nacida en una tierra libre, donde se manifiestan firmemente el interés personal y el individualismo, que se muestra intolerante ante la experiencia administrativa y la educación que 
impulsa la libertad individual mạ́s allá de los debidos límites, presenta peligros junto a beneficios. El individualismo en Norteamérica ha permitido una cierta laxitud en referencia a los asuntos de gobierno, que ha hecho posible el sistema de botín ${ }^{6}$ y todos los daños manifiestos que se derivan de la falta de un espíritu cívico altamente desarrollado. A este respecto se puede observar también la influencia de las condiciones fronterizas al permitir la relajación del honor comercial, la inflación del papel moneda y la especulación bancaria. La frontera colonial y revolucionaria fue la región de donde emanaron las peores formas de una circulación perniciosa. En la guerra de 1812, el Oeste repitió el fenómeno en la frontera de aquel tiempo, en tanto que la especulación y las operaciones bancarias ilegales del periodo de la crisis de 1837 se produjeron en el nuevo cinturón fronterizo de la siguiente serie de estados. Así pues, cada uno de los periodos de relajación de la integridad financiera coinciden con aquellos en que había surgido una nueva serie de comunidades fronterizas y en su mayor parte coincide en el territorio con esas fronteras sucesivas. La reciente agitación populista es un ejemplo pertinente de ese fenómeno. Muchos estados que ahora declaran no tener conexión alguna con los principios populistas, se adhirieron a esas ideas en una etapa anterior de su desarrollo como estados. No cabe esperar que una sociedad primitiva demuestre la misma apreciación inteligente de la complejidad de los intereses de negocios que una sociedad desarrollada. La continua recurrencia de esas zonas en la agitación por el papel moneda es otra evidencia de que la frontera puede ser aislada y estudiada como factor de la mayor importancia en la historia norteamericana.?

El Este ha temido siempre el resultado de un avance de la frontera no regulado y ha intentado frenarlo y guiarlo. Las autoridades inglesas hubieran detenido el avance en las fuentes de los rios tributarios del Atlántico, dejando a los "salvajes disfrutar en paz de sus desiertos con el objeto de que no disminuyera el comercio de pieles", lo que provocó la espléndida protesta de Burke:

Si ustedes suspendieran las concesiones, ¿cuál sería la consecuencia? La gente ocuparía las tierras sin ellas. Ya io ha hecho así en muchos sitios. No pueden mantenerse guarniciones en todos los puntos de esos desiertos. Si echan a la gente de un sitio, recogerá su cosecha anual y se irá a otra parte con sus ganados y rebaños. Muchos de los antiguos colonos sienten ya poco apego por los lugares en que se hallan. Algunos han llegado a las cimas de los montes Apalaches. Desde alli pueden contemplar ante ellos una inmensa llanura, una pradera vasta y rica, una extensión de quinientas millas cuadradas sobre la que vagarán sin que nadie pueda impedírselo; cambiarán sus maneras de acuerdo a sus

${ }^{6}$ El sistema de botín otorgaba cargos públicos a cambio de servicios prestados a algún político triunfador en las elecciones. (N. del T.)

7 No he querido detenerme en las características ilegales de la frontera, pues son suficientemente conocidas. El tahúr, el malhechor, los reguladores de las Carolinas y los vigilantes de California, son tipos de esa franja de escoria que las oleadas de la civilización que avanza llevaban delante y del desarrollo de organos de autoridad espontáneos donde estaba ausente la autoridad legal. El humor, la valentía, la ruda fortaleza, asi como los vicios de la frontera en su peor aspecto, han dejado huellas difíciles de borrar en el carácter, lenguaje y literatura norteamericanos. 
hábitos de vida; pronto olvidarán a un gobierno que los repudia, se convertirán en hordas de tártaros ingleses y, lanzando sobre las fronteras no fortificadas una caballería feroz e irresistible, se convertirán en amos de sus gobernadores, de sus consejeros, de sus recaudadores de impuestos y de sus contadores, así como de todos los esclavos que se unieran a ellos. Tal sería el efecto, a breve plazo, de intentar prohibir como un crimen y suprimir como un mal el mandato y la bendición de la Divina Providencia "creced y multiplicaos". Tal sería el desgraciado resultado del intento de conservar como madriguera de bestias salvajes esa tierra que Dios, como una concesión expresa, ha dado a los hijos de los hombres.

Pero no era sólo el gobierno inglés el que deseaba limitar el avance de la frontera y guiar su destino. Las costas de Virginia y de Carolina del Sur manipularon esas colonias para asegurar el dominio de la costa en sus legislaturas. Washington deseaba colonizar a un estado después de otro en el Noroeste; Jefferson quería dejar sin colonizar el territorio adquirido en Luisiana al norte del paralelo 32 para ofrecerlo a los indios a cambio de las zonas que ocupaban al este del Mississippi. "Cuando hayamos completado la colonización de esa parte -escribe- podremos alinear una cadena de estados en la orilla occidental desde las fuentes a la desembocadura, y asi, hilera tras hilera, avanzar de una manera compacta a medida que nos multipliquemos." Madison llegó al extremo de decir al ministro de Francia que los Estados Unidos no tenian interés alguno en ver que su población se extendiera por la orilla derecha del Mississippi, sino que mâs bien temia tal hecho. Cuando se debatió la cuestión de Oregón, en 1824, Smyth, representante de Virginia, queria trazar una línea invariable como límite de los Estados Unidos, en el borde exterior de dos hileras de estados situados más allá del Mississippi y se quejaba de que los estados marítimos se veían privados de lo mejor de su población ante el ofrecimiento de demasiadas tierras nuevas. Incluso Thomas Benton, el hombre de puntos de vista más amplios acerca del destino del Oeste, declaró en aquella fase de su carrera que "los limites occidentales de la República debian ir a lo largo de la cresta de las Montañas rocallosas y que en el picacho más alto debería erigirse una estatua al legendario dios Término, que nunca habría de ser derribada". Pero resultaron vanos los intentos de limitar los confines, de restringir las ventas de tierras y la colonización y de privar al Oeste de su participación política. Ininterrumpidamente la frontera de la colonización avanzaba, llevando con ella individualismo, democracia y nacionalismo; afectando poderosamente al Este y al Viejo Mundo.

Los esfuerzos más eficaces del Este para regular la frontera tuvieron lugar por medio de su actividad educativa y religiosa, ejercida por la emigración interestatal y por sociedades organizadas. El doctor Lyman Beecher declaró en 1835: "Es también indudable que el destino religioso y político de nuestra nación debe ser decidido en el Qeste", e indicaba que la población del Oeste está compuesta por gente de todos los estados de la Unión y de todas las naciones de Europa, y crece como las aguas de una inundación, exigiendo para su conservación moral la acción inmediata y universal de las instituciones que disciplinan la mente y dan armas a la conciencia y al corazón. Son tan variadas las opiniones y las 
costumbres, reciente e imperfecto el conocimiento y tan dispersos los establecimientos del Oeste, que no puede formarse un sentimiento público homogéneo que haga inmediatamente leyes que creen las instituciones necesarias. $Y$ sin embargo, hacen falta de una manera inmediata, en su expresión más perfecta y potente. Una nación 'nace en un día'... Pero ¿qué será del Oeste si su prosperidad alcanza tal majestad de poder mientras demoran en aparecer esas grandes instituciones necesarias para formar la mente, la conciencia y el corazón de aquel vasto mundo? Es algo que no debe ser permitido... Que ningún hombre del Este se tranquilice a sí mismo y sueñe con la libertad, independientemente de lo que ocurra en el Oeste... El destino del Oeste es nuestro destino."

Al apelar a la conciencia de Nueva Inglaterra, Beecher apela a sus temores con el fin de que otras religiones no aventajen a la suya. El predicador y el maestro de escuela de Nueva Inglaterra dejaron su huella en el Oeste. El temor de que el Oeste se emancipara del control político y económico de Nueva Inglaterra era paralelo al de que pudiera liberarse de los lazos religiosos. Al comentar en 1850 las noticias sobre la rápida extensión hacia el norte de la colonización en Wisconsin, el editor del Home Missionary escribe: "Ciertamente no sabemos si hemos de regocijarnos o entristecernos ante la extensión de nuestra colonización. Al mismo tiempo que simpatizamos con todo aquello que contribuye a aumentar los recursos físicos y la prosperidad de nuestro país, no podemos olvidar que con toda esa dispersión por rincones cada vez más remotos de la tierra, la posibilidad de proporcionar los medios para aumentar la gracia divina se hace cada vez menor." Obrando en consonancia con tales ideas, se establecieron misiones y se erigieron universidades en el Oeste. Del mismo modo que las ciudades costeras como Filadelfia, Nueva York y Baltimore luchaban por la supremacía en el comercio occidental, así también las diversas denominaciones religiosas luchaban por la posesión de aquella región. Con ello, el Oeste fue fertilizado por una corriente intelectual procedente de fuentes de Nueva Inglaterra. Otras regiones enviaron también sus misioneros; pero la verdadera lucha se dio entre las sectas. La disputa por el poder y la tendencia expansiva proporcionada a las diversas sectas por la existencia de una frontera móvil, debe haber tenido importantes resultados sobre el carácter de la organización religiosa en los Estados Unidos. La multiplicación de iglesias rivales en las pequeñas poblaciones fronterizas tuvo unos efectos sociales profundos y duraderos. Los aspectos religiosos de la frontera constituyen un capítulo de nuestra historia que debe ser estudiado.

Las condiciones de la vida de frontera dieron lugar a rasgos intelectuales de profunda importancia. Las obras de los viajeros que recorrieron las diversas fronteras desde los días coloniales describen ciertos rasgos comunes que, a pesar de haberse desvanecido, sobreviven en su lugar de origen aun cuando se haya producido en él una organización social más elevada. El resultado es que el intelecto norteamericano debe a la frontera sus notables características. Esa rudeza y fortaleza combinada con la agudeza y la curiosidad; esa disposición mental práctica e inventiva, rápida para encontrar recursos; ese control magistral de las cosas materiales, privado de sentido artístico, pero poderosamente eficaz para con- 
seguir grandes fines; esa energía incansable y nerviosa; ${ }^{8}$ ese individualismo dominante que labora para el bien y para el mal, y al mismo tiempo esa vivacidad y esa exuberancia que resultan de la libertad, ésos son los rasgos de la frontera o aquellos producidos en otros sitios como consecuencia de la existencia de la frontera. Desde los días en que la flota de Colón navegó en las aguas del Nuevo Mundo, América ha venido a significar lo mismo que oportunidad, y el pueblo de los Estados Unidos ha adquirido su temperamento en la incesante expansión no sólo abierta ante él, sino impuesta en muchas ocasiones. Sería un mal profeta quien afirmase que ya ha cesado por completo el carácter expansivo de la vida norteamericana. El movimiento ha sido su factor dominante, y a no ser que ese entrenamiento no tenga efecto alguno sobre un pueblo, la energía norteamericana seguirá pidiendo constantemente un campo más amplio para su ejercicio. Pero nunca se ofrecerán de nuevo esos dones de tierras libres. En la frontera se rompen los vínculos de la costumbre y triunfa el desenfreno. No hay tabula rasa. El inflexible medio ambiente norteamericano está allí, con sus imperiosas incitaciones a que se acepten sus condiciones; también están alli los hábitos heredados en cuanto a la forma de hacer las cosas; $y$, sin embargo, a pesar del medio ambiente, a pesar de la costumbre, cada frontera proporcionó ciertamente un nuevo campo de oportunidad, una puerta de escape a la esclavitud del pasado; y la frontera se ha visto acompañada por una frescura, una confianza y un desprecio por la vieja sociedad, junto con una impaciencia ante sus imposiciones e ideas e indiferencia ante sus enseñanzas. Lo que el mar Mediterráneo fue para los griegos, rompiendo los lazos de la costumbre, ofreciendo nuevas experiencias, dando lugar a nuevas instituciones y actividades, fue la frontera siempre en retirada para los Estados Unidos, en mayor medida y de manera directa, y remotamente para las naciones de Europa. Y ahora, cuatro siglos después del descubrimiento de América, al cabo de cien años de vida constitucional, la frontera ha desaparecido y con su desaparición se ha cerrado el primer periodo de la historia norteamericana.

${ }^{8}$ Los viajeros coloniales están de acuerdo en observar el carácter flemático de los colonos. Frecuentemente se ha formulado la pregunta de cómo un pueblo tai pudo desarrollar esa energía nerviosa y forzada que ahora les caracteriza... La transición aparece bien marcada al final de la guerra de 1812 , periodo en que el interés se centraba en el desarrollo del Oeste, y el Oeste se caracterizaba por su incansable energía. 